\title{
Income Taxation in a Frictional Labor Market
}

\author{
Joel Shapiro* \\ Universitat Pompeu Fabra
}

July 2001

\begin{abstract}
A new model of wage dispersion is used to examine welfare aspects of income taxation. The model retains the dynamics of wage posting models while exogenizing search effort, therefore allowing more insight into policy issues. The results highlight effects that standard analyses do not take into account. The optimal income tax should depend on an incidence effect between workers and firms. This incidence effect arises from firms trying to lower wages as much as possible. An employment tax proves, in certain cases, to be the best method to encourage labor force participation.

JEL Classifications: D83,H21,H22

Keywords: wage posting, optimal income taxation, search
\end{abstract}

\footnotetext{
*Contact: Joel Shapiro, Universitat Pompeu Fabra, Departament D'Economia i Empresa, Ramon Trias Fargas, 25-27, 08005 Barcelona SPAIN. email: joel.shapiro@econ.upf.es phone: (34) 935422718
} 


\section{Introduction}

The economics of information has added a great deal of complexity and reality to standard models of market clearing through asymmetries, rigidities, and frictions. One area in particular that has provoked much examination is the determination of wages. While it is unclear whether workers receive their marginal product, many analyses of policy incorporate this as an assumption. The optimal income tax literature builds on the assumption that wages are given exogenously. A main purpose of this paper is to show that there are important reasons to model worker-firm interaction.

In order to accomplish this, we use a model of search. Search theory ${ }^{1}$ attempts to explain wage formation as a non-centralized phenomenon (as opposed to the Walrasian auctioneer). This certainly corresponds to individuals' experiences in the labor market, and indeed offers a strong explanation of how wage dispersion may come about. We avoid difficulties inherent in using search models for policy applications by exogenizing search effort. We assume that each worker has the same number of job applications. This new model has similar characteristics and dynamics of other wage posting models (for example, Burdett and Judd (1983)), but abstracts away from worker search behavior in order to study other important market features. The approach allows very clear insight into the issues analyzed.

Using this environment, we study the effect of income taxation on the labor force participation of heterogeneous workers. Standard models of income taxation focus on how labor decisions are distorted by tax schedules. Empirical evidence, however, shows that the responsiveness of labor to tax or income changes is very small (for a survey of this literature, see Hausman (1985)). Rigidities in the labor market make it costly to change one's schedule within a job or to switch jobs. In contrast, potential entrants into the labor market do not face such rigidities, and should respond to income incentives when deciding on jobs. The

\footnotetext{
${ }^{1}$ For a survey, see Mortensen and Pissarides (1999).
} 
work of Pissarides (1985) and Smith (1994) moves in this direction, looking at how taxation affects unemployment flows in bilateral search models. Manning (2001) focuses on the issue of taxation's effects on labor supply in a search model.

We assume workers differ by their disutility of education, but all must pay the same monetary cost in order to be able to produce quantity $f$ when employed. Those with high enough disutility would rather not enter the labor market. While the government would prefer more workers to participate than do in equilibrium (Lemma 3), taxation decreases incentives to do so. We find that employment taxes may decrease this incentive less than any other possible tax, because they force firms to bear part of the tax burden. This incidence effect is created by the downward pressure on wages.

\section{The Model}

We construct the model by assuming that the working population can be characterized by one skill/education level. While this does not resemble the labor market in general, it may resemble a part of a segmented labor market. The motivating force behind this is to display strong effects that are robust in a number of environments in a simple manner.

\subsection{Labor Market Frictions}

The main assumption in this paper is that of an exogenous application/search process ${ }^{2}$. This allows us to highlight labor market participation effects and firms' decisions in a tractable manner. It makes sense that people of similar educations undergo similar search processes, and that some labor markets impose strict application processes (government service, for example). The application process that we specify utilizes the basic dynamics of nonsequential

\footnotetext{
${ }^{2}$ Many search models assume an exogenous search process, e.g. Varian (1980) and Stahl (1989), but obtain wage dispersion from the heterogeneity of agents. Here all workers searching for jobs are homogeneous and search in the exact same way. Ex-post heterogeneity creates the dispersion in wages.
} 
search established in Burdett and Judd (1983) ${ }^{3}$. Consider the labor market interactions of a mass $M$ of firms and a mass $\mu$ of workers. Each firm has one position available. Workers enter the labor market at some cost and apply to $n$ firms drawn at random from the available pool. If all workers only apply to one firm, then firms will set wages at the workers' reservation utility since workers will not have the option to refuse an offer. This is the 'Diamond-paradox'. However, if workers apply to more than one firm, some will have a positive probability of being able to refuse a low offer, putting pressure on firms to raise their wages in order to increase the probability of getting a worker. This creates a wage distribution in equilibrium ${ }^{4}$. Therefore, the existence of some probability with which workers can compare wages drives wage dispersion. In our model the probability of a worker's application succeeding (yielding a job offer) is between 0 and 1, implying that more than one application will allow some workers to compare wages. To obtain wage dispersion with closed form solutions, we limit the number of applications to two.

Since workers are homogeneous in terms of their productivity, firms choose randomly among them. If a worker gets more than one offer, she decides which offer to accept. This is enough to allow us to define successful application probabilities.

Lemma 1 With $M$ firms and $\mu$ of the population participating in the application process:

1) The probability that an application leads to a job offer is $\lambda=\frac{1-e^{-\frac{2 \mu}{M}}}{\frac{2 \mu}{M}}$

2) The probability that a firm receives no applications is $e^{-\frac{2 \mu}{M}}$

This is a well known result; the derivation is relegated to the appendix.

\footnotetext{
${ }^{3}$ Burdett and Judd (1983) is actually a model of price dispersion. The description above translates it into a model of wage dispersion (price $=$ wage, consumers $=$ workers).

${ }^{4}$ Here we don't have to worry about the 'Bertrand result' where firms face so much pressure to raise wages that wage distribution is an atom at the highest possible value. This only occurs when workers sample more than one wage with probability 1 , which can't occur in the labor market we describe.
} 


\subsection{Labor Market Participants}

\section{Firms}

A homogeneous mass $M$ of firms each has only one job to offer. They are capacity constrained; they can only accommodate one worker profitably. The assumption of a one worker - one firm match is also employed in Montgomery (1991) and Acemoglu and Shimer (2000) in order to discuss the impact of tightness in the labor market. Since we will normalize the mass of workers to $1, M$ represents the firm-worker ratio. Another way to think about this is that firms may have many jobs available, but each position recruits separately.

Firms then enter the labor market, posting wages and matching with workers as described above. A match produces output $f$, which is sold at the common price of 1 . The firms' wage distribution when $\mu$ workers apply for positions results from an equal profits condition, that is, for all $w$ :

$$
\left(1-e^{-\frac{2 \mu}{M}}\right)((1-\lambda)+\lambda G(w))(f-w)=\pi
$$

The first term equals, given Lemma 1, the probability that the firm receives an application at all. Given that it does receive at least one application, the second term represents the probability that the randomly chosen worker will accept the firm's offer of $w$, meaning that the worker has no offer larger than $w$ (where $G(w)$ represents the distribution of wages over the interval $[a, b])$.

Since the firms who employ workers at the lowest wage $w=a$ only employ those who can't switch firms, these firms have an incentive to lower their wages down to the point where workers refuse to work. A reservation point of 0 for workers implies that $a=0$ and allows us to solve for firm profits. Profits equal $\left(1-e^{-\frac{2 \mu}{M}}\right)(1-\lambda) f$. The equal profits condition now defines the cumulative distribution $G(w)$. Using the endpoint condition $G(a)=0$, we can determine that $G(w)=\frac{1-\lambda}{\lambda}\left(\frac{f}{f-w}-1\right)$ and $b=\lambda f$. 


\section{Workers}

A mass 1 of workers differ only by their cost of entering the labor market. This cost is fixed and is indexed by the parameter $\theta$. We will think of this cost as an education cost, although it can be thought of as any type of fixed cost of entry into the labor market. There are many potential factors that could make education costly to an individual. Such factors include ability, taste for leisure, family situation, and borrowing constraints. The index $\theta$ varies between $\theta_{0}$ and $\theta_{1}$, and has a c.d.f. of $P(\theta)$. A worker of type $\theta$ who has not entered the labor market but has received the common level of education has the utility function Expected Income $-\theta$.

Expected Income consists of labor market income and assets. Each worker is a shareholder in the firms, giving them assets beyond their labor earnings. Therefore, if they don't participate in the labor market, their utility is equal to their assets.

In this framework, the workers' only decision is that of participation in the education process. We define a cutoff $\theta^{*}$ such that $\theta^{*}=$ Labor Income, where those above the cutoff don't participate in the education process (and therefore the labor market) and those below do. The cutoff doesn't depend on assets, as they remain the same whether one participates or $\operatorname{not}^{5}$.

We also define $\mu=P\left(\theta^{*}\right)$ as the fraction of those participating. Participation, of course, doesn't imply employment. There are two types of unemployed people in this model. One type participates in the labor market, but doesn't succeed in finding a job, while the other type doesn't participate at all (1- $\mu$ of the population).

The expected labor income of a participating worker can now be expressed as:

\footnotetext{
${ }^{5}$ It is important to observe that by including assets, taxation of the firm does affect workers directly (and not just through wages). However, assets don't affect their participation decisions, which is the distortion that a surplus maximizing planner is concerned with.
} 


$$
\lambda^{2} \int_{a}^{b} 2 w G(w) g(w) d w+2 \lambda(1-\lambda) \int_{a}^{b} w g(w) d w
$$

where the first term represents the product of the probability of two successful applications and the expectation of the top wage given two samples, and the second term represents the product of the probability of one successful application and the expected wage given one sample. It is worth noticing that the expression for labor income bears some resemblance to the firms' equal profits condition.

Using the basic setup established for workers and firms, we can now explore the dynamics of the model.

Lemma 2 Firms' profits decrease with the number of firms and increase with the number of productive workers. The range of the wage distribution increases with the number of firms and decreases with the number of workers.

Proof. To prove the statement about firm's profits we begin by rewriting the profits as $\left(1-e^{-q}\right)\left(1-\frac{1-e^{-q}}{q}\right) f$, substituting for $\frac{2 \mu}{M}$ with $q(\mu, M)$. The sign of the derivative with respect to $q$ depends on the sign of the expression $(2 q+1) e^{-2 q}+\left(q^{2}-2 q-2\right) e^{-q}+1$. The expression must be greater than $\left(q^{2}+2 q+1\right) e^{-2 q}+(-2 q-2) e^{-q}+1$, which simplifies to $\left((1+q) e^{-q}-1\right)^{2}$ and must therefore be positive. Since $\frac{d q}{d \mu}$ is positive and $\frac{d q}{d M}$ is negative, the chain rule gives us our result.

We prove the second statement by showing that the probability an application is successful $(\lambda)$ decreases with $q . \lambda$ can be written as $\frac{1-e^{-q}}{q}$, and its derivative with respect to $q$ is $(1+q) e^{-q}-1$. Since $\mu$ varies between 0 and 1 and $M$ is non-negative, $q$ may vary between 0 and $\infty$. The derivative of the expression in brackets is non-positive $\left(-q e^{-q}\right)$ and the expression evaluated at 0 equals 0, implying it is always non-positive. Again, application of the chain rule yields our result. 
The intuition here is straightforward. Larger numbers of firms compete away profits and larger numbers of workers allow firms to be more selective and lower wages. Similarly, the probability of getting a job decreases with worker congestion and increases with added firms.

\subsection{Labor Market Equilibrium}

We can simplify the problem considerably by substituting the wage distribution into the worker's expected income. This yields the expression $\lambda^{2} f$. This expression has an intuitive meaning; using the 'Diamond paradox' (if all applicants have only one successful application, the wage will be the reservation wage of 0 ) and the 'Bertrand result' (if all applicants have two successful applications, the wage will be bid up to $f$ ) we can represent expected income as the probability of two successful applications multiplied by its payoff $(f)$ plus the probability of one or no successful applications times its payoff $(0)$, or $\lambda^{2} f+\left(2 \lambda(1-\lambda)+(1-\lambda)^{2}\right) 0$.

We have already seen that the decision of the worker who is indifferent between participating and not participating defines $\mu^{*}$ implicitly: $\theta^{*}=\lambda^{2} f$ can be rewritten as

$$
\mu^{*}=P\left(\lambda^{2} f\right)
$$

The left-hand side obviously increases with $\mu$, and from lemma 2, the right hand side clearly decreases with $\mu$, indicating that an equilibrium will always exist (although a corner solution could occur if $\left.\theta^{*} \notin\left[\theta_{0}, \theta_{1}\right]\right)$.

\section{Optimal Taxation}

By incorporating a frictional labor market, we develop a new theory of the optimal construction of income taxes. In discussions of optimal income taxation (dating back to Mirrlees (1971)), the wage generating process is exogenous and workers receive their exact marginal product. In addition, the literature considers unemployment a choice and not dependent 
on labor market conditions. Pissarides (1985) and Smith (1994) discuss positive aspects of taxation when wages are determined by bilateral search and bargaining. The wage pressures in our model are not captured in a bargaining model, and critically affect results. Specifically, we find that an incidence effect between firms and workers is crucial in determining the optimal policy.

We now consider the interaction between participation and welfare in an environment where the government may use taxation to raise revenue. We assume that the number of firms $M$ is fixed. The government's main concern aside from revenue lies in maximizing surplus. As each filled job leads to output valued at $f$, surplus is measured here as employment $x$ output - costs. Alternatively, this can be expressed as workers' income + firms' profits - costs. The government's optimal value of participation, $\mu_{G}$, which maximizes surplus is associated with the type $\theta_{G}$ that solves the problem:

$$
\max _{\tilde{\theta}} \int_{\theta_{0}}^{\tilde{\theta}}\left\{\left(\lambda^{2}+2 \lambda(1-\lambda)\right) f-\theta\right\} p(\theta) d \theta \quad \text { s.t. } \theta_{0} \leqslant \tilde{\theta} \leqslant \theta_{1}
$$

Recognizing that $\lambda$ is a function of $\mu$ and hence $\theta$, the following lemma provides insight into the optimal choice of $\mu$.

Lemma 3 Given an interior solution for $\mu^{*}$, the government's optimal participation rate is greater than the equilibrium participation rate: $\mu_{G}>\mu^{*}$

The proof of this lemma is in the appendix.

The optimality of greater participation was not a foregone conclusion. There are two opposing effects on surplus when participation is increased. The first is an externality effect. By increasing the size of the working population, the probability of matching for all workers decreases. With this effect, we should expect to see the government internalizing the externality that the marginal worker imposes on the other workers, implying an optimal participation rate less than the equilibrium rate. The second effect, which we call the surplus 
effect, stems from the fact that workers only take into account the element of matching that elevates wages, which as we saw previously was the probability of two successful applications, or $\lambda^{2}$. Surplus, on the other hand, is generated by any successful application, which occurs with probability $\lambda^{2}+2 \lambda(1-\lambda)$. Lemma 3 states that the surplus effect dominates the externality effect.

We consider first the impact of a simple proportional tax. Suppose that the government taxes income for all individuals at a rate of $t_{p}$. Since the point at which workers refuse to work remains zero, firms maintain the original wage distribution. The participation equation ${ }^{6}$ must change to reflect the tax: $\mu_{p}=P\left(\left(1-t_{p}\right) \lambda_{p}^{2} f\right)$. This shifts down the right hand side, reducing the participation rate $^{7}$, which, from a welfare standpoint, widens the participation problem $\left(\mu_{p}<\mu^{*}<\mu_{G}\right)$ and hence decreases total surplus.

We now consider an employment $\operatorname{tax}^{8}, t_{e}$, levied on all people who participate in the labor market. Firms must induce workers to participate ${ }^{9}$, moving up the wage distribution to begin at $a=t_{e}$. From this, we see that the top wage has increased $\left(b=f-\left(1-\lambda_{e}\right)\left(f-t_{e}\right)\right)$ but the range of the wage distribution has shrunk. This implies that workers' expected incomes do not just decrease by $t_{e}$, there is a feed-through mechanism in the firms' wage posting. Indeed, with the lump sum tax expected income decreases from $\lambda_{e}^{2} f$ to $\lambda_{e}^{2}\left(f-t_{e}\right)$. This yields a similar participation equation: $\mu_{e}=P\left(\lambda_{e}^{2}\left(f-t_{e}\right)\right)$. Again, the right hand side shifts down with $t_{e}$, meaning that participation and hence total surplus both decrease with the lump sum tax.

We now have all of the tools necessary for analyzing questions of incidence. Here, we separate two incidence effects, a first-order effect and a second-order effect. The first-order

\footnotetext{
${ }^{6}$ We add subscripts to $\mu$ and $\lambda$ to indicate that they depend on the tax.

${ }^{7}$ Equivalently, one could use the implicit function theorem to show this.

${ }^{8}$ Fershtman and Fishman (1994) consider a sales tax (fixed tax irrespective of price) within the actual Burdett and Judd (1983) model, and look at how average price is affected.

${ }^{9}$ The potential for net negative wages here are a result of the normalization of workers' reservation utilities to zero. By adusting the reservation utilities to a positive number, net negative wages would disappear, and consequently have little meaning.
} 
effect captures the direct impact of taxes, while the second-order effect accounts for how the taxes change the workers' participation level (and how that subsequently affects who bears the tax burden). Incidence is a question often not addressed in examinations of income taxation because the income/wage distribution is modeled exogenously. In such a model, it would only be possible to observe the second-order effect, if any effect is observed at all.

The proportional tax exhibits only the second-order incidence effect. Firms' profits remain the same and the workers bear the direct burden of the tax, decreasing to $\left(1-t_{p}\right) \lambda_{p}^{2} f$. Indirectly, the workers reduce their participation and, from lemma 2, we see that this reduction increases the payoff to participating workers while decreasing the profits of firms. The employment tax, on the other hand, exhibits both effects. Both firms and workers feel the tax directly. Firms are forced to share part of the tax because they must raise wages in order to encourage employment. Their profits decrease on the first order to $\left(1-e^{-\frac{2 \mu}{M}}\right)\left(1-\lambda_{e}\right)\left(f-t_{e}\right)$. With the decrease in expected income, less workers are induced to participate. This partly mitigates the fall in active workers' expected incomes and makes firms' losses even greater.

What is the difference between the taxes? Is one more efficient than the other? To analyze these questions we employ the approach of looking at the outcomes of each tax when there is a fixed revenue requirement of $R$ and find a very intriguing and simple result.

Proposition 4 Given a fixed revenue requirement of $R$, employment taxes generate more participation than proportional taxes.

Proof. Under a proportional tax, revenues from workers equal $t_{p} \lambda_{p}^{2} f \mu_{p}$ (the average revenue per worker multiplied by the population that participates and the tax rate $\left.t_{p}\right)$. For the employment tax, revenue from workers amounts to $\mu_{e}\left(-\lambda_{e}^{2}+2 \lambda_{e}\right) t_{e}$ (the labor supply multiplied by the tax).

The cutoff rule of the participation equation for proportional taxes and employment taxes are defined by $P\left(\left(1-t_{p}\right) \lambda_{p}^{2} f\right)$ and $P\left(\lambda_{e}^{2}\left(f-t_{e}\right)\right)$, respectively. Setting the tax revenues 
from each tax equal to $R$ and plugging the results into their corresponding cutoff rule yields $P\left(\lambda_{p}^{2} f-\frac{R}{\mu_{p}}\right)$ (for the proportional tax) and $P\left(\lambda_{e}^{2} f-\frac{R}{\mu_{e}}+2 \lambda_{e}\left(1-\lambda_{e}\right) t_{e}\right)$ (for the employment tax). It is obvious that for equal levels of $\mu$, the proportional tax cutoff rule is less than the employment tax cutoff rule. The participation equation therefore implies that $\mu_{p}<\mu_{e}$.

The intuition behind this result comes from the analysis of incidence. Since firms must effectively share in the payment of the lump sum taxes (the first order effect), the amount that the workers pay is less than when the firms do not share at all. The larger earnings increase worker participation. This makes the welfare differences between the two types of taxes unambiguous. Proposition 4 gives us the ranking $\mu_{p}<\mu_{e}<\mu^{*} \leqslant \mu_{G}$, which implies that in order to maximize welfare, the government should adopt an employment tax over a proportional tax.

Potential workers respond to incentives and their participation depends on a marginal condition. Firms, on the other hand, recruit as long as profits are non-negative making them ideal to bear the burden of the tax. The incentive of firms to lower their wages as much as possible allows the shifting of the burden by altering the workers' effective reservation point.

Clearly the proportional tax and the employment tax are extreme examples, but they provide all of the insight that is necessary in this environment. Suppose we want to analyze the effects of different progressive taxes. First consider a tax that consists of the proportional rate $t_{z}$ and a fixed amount $Z$ given to each worker. This tax is progressive in average tax rates. If the fixed amount is given to anyone who files a tax return (i.e. even those who do not participate in the labor market) as in a Negative Income Tax, then the effect on participation is equivalent to the proportional tax where $t_{z}=t_{p}$. If the fixed amount is only given to those who report income, then firms are able to appropriate part of the transfer since the worker's effective reservation point moved down. This makes it more difficult for the government to raise revenue and encourage participation, decreasing the efficiency of the $\operatorname{tax}\left(\mu_{z}<\mu_{p}<\mu_{e}<\mu^{*} \leqslant \mu_{G}\right)$. If the government uses a tax that is progressive in marginal 
rates (say $t_{1}$ up to some wage $w_{1}, t_{2}$ for income above $w_{1}$ ), there is no first order effect, and any second order effect will be the same as a revenue equivalent proportional tax.

\section{Conclusion}

Since workers in this model are homogeneous in terms of skill, redistributive goals don't have the same relevance as in models of optimal income taxation. We have, however, illustrated some critical factors that do not arise in Mirrlees' and subsequent analyses. That literature does not include wage setting by firms or frictional unemployment, both of which are important to our results and in understanding the incomes of individuals. Taxation distorts participation decisions, but an incidence effect between workers and firms due to wage pressures could potentially reduce distortions.

Wage dispersion is integral to the results in this paper. Since most labor markets are characterized by some form of variance in wages, using such an approach makes sense. We assume that firms post wages and, in order to concentrate on taxation and welfare issues, we abstract away from equilibrium search patterns, assuming each worker makes two job applications. This new model yields intuitive results and allows for much tractability. Even though the model in this paper represents a stylized version of labor market frictions, the results are general to both other search models and non-search models. The results will hold when changes in income move with changes in participation and downward pressure on wages exists ${ }^{10}$.

Some extensions could prove interesting. Heterogeneous firms should deepen divisions in the labor market. By making ability heterogeneous and unobservable, thereby introducing adverse selection, this model could be unified with Mirrlees type optimal income taxation models.

\footnotetext{
${ }^{10}$ In another version of this paper, workers could invest in their probability of being productive (i.e. participating). This led to very similar results.
} 


\section{Appendix}

\section{A Proof of Lemma 1}

Suppose there are $\mathrm{n}$ firms and $\mathrm{q}$ workers. The probability of a productive worker matching equals:

$$
\sum_{i=0}^{q} \operatorname{Pr}(i \text { others show up }) \operatorname{Pr}(\text { hired } \mid i \text { show up })
$$

or:

$$
\sum_{i=0}^{q}\left(\begin{array}{l}
q \\
i
\end{array}\right)\left(\frac{1}{n}\right)^{i}\left(1-\frac{1}{n}\right)^{q-i} \frac{1}{i+1}
$$

simplifying (and using the binomial theorem), this yields:

$$
\frac{n}{q+1}\left(1-\left(1-\frac{1}{n}\right)^{q+1}\right)
$$

since there is a positive mass of workers and firms, we take the limit as $n$ and $q$ approach

$\infty$ (noting that the worker application-firm ratio equals $\frac{2 \mu}{M}$ ) and achieve our result. The probability a firm receives no productive workers is found by taking same limit of:

$$
\left(1-\frac{1}{n}\right)^{q}
$$

Similar probabilities are used in Blanchard and Diamond (1994), Acemoglu and Shimer (2000) and Lang and Dickens (1992). The first to use this urn-ball process was Butters (1977). 


\section{B Proof of Lemma 3}

We first differentiate the government's objective function (equation 4) with respect to $\tilde{\theta}$, noting that $\frac{d \mu}{d \tilde{\theta}}=p(\tilde{\theta})$ and that $\lambda$ is evaluated at $\theta=\tilde{\theta}$ :

$$
\frac{d}{d \mu}\left\{\left(\lambda^{2}+2 \lambda(1-\lambda)\right)\right\} \times \mu f p(\tilde{\theta})+\left\{\left(\lambda^{2}+2 \lambda(1-\lambda)\right) f-\tilde{\theta} c\right\} p(\tilde{\theta})
$$

For all $\tilde{\theta}$ less than $\theta^{*}$, this expression is greater than:

$$
\frac{d}{d \mu}\left\{\left(\lambda^{2}+2 \lambda(1-\lambda)\right)\right\} \times \mu f p(\tilde{\theta})+\left\{\lambda^{2}+2 \lambda(1-\lambda)-\left(\lambda\left(\theta^{*}\right)\right)^{2}\right\} f p(\tilde{\theta})
$$

Lemma 2 lets us say that $\lambda\left(\theta^{*}\right)<\lambda(\tilde{\theta})$ (again for all $\tilde{\theta}<\theta^{*}$ ), which means equation 11 is also greater than:

$$
\frac{d}{d \mu}\left\{\left(\lambda^{2}+2 \lambda(1-\lambda)\right)\right\} \times \mu f p(\tilde{\theta})+2 \lambda(1-\lambda) f p(\tilde{\theta})
$$

Simplifying and substituting $k=\frac{M}{\mu}$ yields:

$$
e^{-\frac{2}{k}}\left(-k+2+e^{-\frac{2}{k}} k\right) f p(\tilde{\theta})
$$

The sign depends on the middle expression which can be shown to be decreasing for all $k>0$ and, using L'Hospital's rule, the limit as the expression approaches 0 (from the right) is equal to 2 and the limit as the expression approaches $\infty$ is equal to 0 . This means the expression is positive and consequently allows us to say equation 11 is positive (for $\tilde{\theta}<\theta^{*}$ ), proving the lemma. 


\section{Acknowledgments}

I thank Patrick Bolton, Harvey Rosen, Robert Shimer, Karen Conneely, and Kosuke Aoki for excellent comments and suggestions. I have also benefitted from comments from the Princeton Public Finance Working Group. Financial support from the Woodrow Wilson Foundation is appreciated.

\section{References}

[1] Acemoglu, D., Shimer, R., 2000. Wage and Technology Dispersion. Review of Economic Studies 67, 585-607.

[2] Blanchard, O. J., Diamond, P., 1994. Ranking, Unemployment Duration, and Wages. Review of Economic Studies 61, 417-434.

[3] Burdett, K. and Judd, K. L., 1983. Equilibrium Price Dispersion. Econometrica 51, 955-969.

[4] Butters, G. R., 1977. Equilibrium Distributions of Sales and Advertising Prices. Review of Economic Studies 44, 465-491.

[5] Fershtman, C. and Fishman, A., 1994. The 'perverse' effects of wage and price controls in search markets. European Economic Review 38, 1099-1112.

[6] Hausman, J. A., 1985. Taxes and Labor Supply. In: Auerbach, A.J., Feldstein, M. (Eds.). Handbook of Public Economics: Volume I. North Holland, New York.

[7] Lang, K., Dickens, W. T., 1992. Labor Market Segmentation, Wage Dispersion and Unemployment. NBER Working Paper \#4073.

[8] Manning, A., 2001. Labour Supply, Search and Taxes. Journal of Public Economics 80, 409-434. 
[9] Mirrlees, J. A., 1971. An Exploration in the Theory of Optimum Income Taxation. Review of Economic Studies 38, 175-208.

[10] Montgomery, J. D., 1991. Equilibrium Wage Dispersion and Interindustry Wage Differentials. Quarterly Journal of Economics 109, 163-179.

[11] Mortensen, D. T., Pissarides, C. A., 1999. New Developments in Models of Search in the Labor Market. In: Ashenfelter, O., Card, D. (Eds). Handbook of Labor Economics: Volume 3. Elsevier Science: Amsterdam.

[12] Pissarides, C., 1985. Taxes, Subsidies and Equilibrium Unemployment. Review of Economic Studies 52, 121-133.

[13] Smith, E., 1994. Taxation in a two-sided search model. Journal of Public Economics 54, $423-435$.

[14] Stahl, D. O., 1989. Oligopolistic Pricing with Sequential Consumer Search. American Economic Review 79, 700-712.

[15] Varian, H. R., 1980. A Model of Sales. American Economic Review 70, 651-659. 